\title{
Emotional pedagogy and the gendering of social and emotional learning
}

\section{Rhiannon Evans}

To cite this article: Rhiannon Evans (2017) Emotional pedagogy and the gendering of social and emotional learning, British Journal of Sociology of Education, 38:2, 184-202, DOI: 10.1080/01425692.2015.1073102

To link to this article: http://dx.doi.org/10.1080/01425692.2015.1073102
(c) 2015 The Author(s). Published by Informa UK Limited, trading as Taylor \& Francis Group
Published online: 11 Aug 2015.

Submit your article to this journal $\pi$

Џll Article views: 1079

Q View related articles ¿

View Crossmark data $₫$ 


\title{
Emotional pedagogy and the gendering of social and emotional learning
}

Rhiannon Evans*

\author{
DECIPHer, School of Social Sciences, Cardiff University, Cardiff, UK
}

(Received 10 July 2014; final version received 18 May 2015)

Social and emotional learning (SEL) has predominantly been conceptualised as a neurological process, which has precluded understanding of how social, cultural and material discourses inform the expression of emotional experiences. Gender remains a notable omission. This article explores the micro-practices through which gender structures the development of young people's emotional subjectivities within the context of a school-based SEL intervention. Particular emphasis is placed on the gendering strategies utilised by educational professionals during the course of their emotional pedagogy. Three strategies are considered: the overt coercion of girls to demonstrate their learning; the permission of boys' passivity, with their docile bodies being indicated as a signifier of participation; and the restricting of occasions for emotional expression in accordance with perceived gender norms. Efforts to inculcate students with a gendered emotional subjectivity mean that differential learning opportunities are on offer, raising concerns about the introduction of new forms of gendered educational inequalities.

Keywords: social and emotional learning; wellbeing; pedagogy; school; intervention; implementation

\section{Background}

In recent years there has been an explosion of interest in social and emotional learning (SEL), as part of both educational theory and praxis. Indeed, an 'ethos of emotionality' has pervaded the activity of educational institutions (Gillies 2011), achieving articulation through the constructs of emotional intelligence, emotional literacy, positive development and wellbeing (Watson et al. 2012). Beyond a burgeoning array of school-based interventions (Durlak et al. 2011; Weare and Nind 2011), the ascendancy of emotion has been most acutely felt within education evaluative standards. In Wales, the school inspectorate's Common Inspection Framework assesses wellbeing as a primary outcome indicator (Estyn 2010), with this priority being

\section{*Email: EvansRE8@cf.ac.uk}


reflected by Education Scotland (2013). Wellbeing was also included as a criterion of educational effectiveness in England in 2009, before being removed as part of a re-orientation towards the academic curriculum (Ofsted 2013).

The genesis of SEL can be largely traced to Daniel Goleman's (1996) seminal publication Emotional Intelligence. Offering a neurological, individualistic conceptualisation of competency in this area, Goleman advocates the conquering of emotionality through the practised application of the rational self. Numerous interventions demonstrate theoretical alignment with this perspective, including the PATHS curriculum (Greenberg et al. 1995) and the English Government's Social and Emotional Aspects of Learning (SEAL) programme (Department for Children, Schools and Families 2007; Department for Education and Skills 2005). These interventions involve the systematic teaching of skill sets, so that students may master normatively undesirable emotions. Such approaches are contested as promulgating a deficit model of SEL, where focus on the proficiency of the individual precludes understanding of the social, cultural and material discourses that inform the meaning and expression of emotional experiences (Cigman 2008, 2012; Craig 2007; Gillies 2011).

The de-contextualisation and de-politicisation of emotion has led to a particular elision of discourses of gender within SEL intervention and assessment. Where evaluation has considered its influence, this has been through subgroup analysis, with gender being demarcated through the male and female binary. Reports of intervention effectiveness according to these categories are equivocal, with contrary differential impacts being indicated across programmes (Weare and Nind 2011). Interventions orientated to externalised behaviours, such as overt violence and relational aggressiveness, have been found to resonate more clearly with male students (Adi et al. 2007). Conversely, the initial piloting of the SEAL programme indicated a decrement in outcome for boys. Craig (2007) hypothesised that these students interpreted the intervention as the feminisation of schooling, and the colonisation of emotion was rejected for disrupting the narrative of being male. Yet while this tentative and somewhat crude exploration suggests a potential significance for gender in structuring SEL, the micro-politics and practices through which it permeates intervention actions and interactions, working to constitute and reconstitute emotional subjectivities, demand further theorisation and empirical examination.

One particularly neglected and untroubled aspect is the role of educational professionals who are charged with intervention delivery, and how their assumptions around emotionality may translate into the gendering of students' SEL. Interrogation of these implicit understandings is of paramount importance, because despite teachers being required to provide what Gillies (2011) terms 'emotional pedagogy', there remains a dearth of specialist training (Kidger et al. 2010). Even in more formalised SEL 
interventions, accompanying instructional handbooks rarely force the professional to question their own beliefs and boundaries around emotional expression; they simply serve as conduits in the transference of knowledge. However, if we are to understand how gender structures the development and performance of emotionality, we need to explore how gendering processes emerge and infuse learning experiences. As part of this we must attend to the role of educational professionals' emotional pedagogic practices in discursively inscribing gendered emotional subjectivities upon students. This article explores the range of gendering strategies performed by educational professionals in the delivery of a SEL intervention, and how they introduce differential learning opportunities for boys and girls, potentially giving rise to new forms of educational inequalities.

\section{Constructing gendered differences through emotional pedagogy}

The nature of educational institutions is to position students in relation to a normative framework of hierarchical binaries, thus enforcing clear signifiers of difference. Indeed, the relative nature of success ensures that the achieving student can only exist in relation to the failing one, with both being necessary subject positions (Benjamin 2001, 2002a, 2002b, 2003; Hall et al. 2004). This discourse of difference has been most salient within the academic standards agenda, where the presence of league tables, combined with the commodification of achievements in the form of ascribed grades, has resulted in a hierarchy of pupil worthiness (Benjamin 2003; Hall et al. 2004). The desirous student thus becomes the desired student, with their worth being augmented when they comply with the system, fulfil teachers' expectations and invest in institutional notions of success (Hall et al. 2004). Yet while students are ostensibly encouraged to strive for achievement and transcend their positioning within hierarchies of worthiness (Benjamin 2003), this capacity is inhibited by educational practices that reify indices of differences.

Gender remains one of the most entrenched if tacit organising frameworks employed by educational institutions in the differentiation of students. An intractable association between masculinity and academic underperformance has been constructed and sustained through a number of moral panics (Benjamin 2001; Haywood and Mac an Ghaill 2012; Renold 2001). Within this context, increased attention has been paid to the role of teachers in gendering the educational experience through their pedagogic practices. In their insightful observation of curriculum delivery, Ivinson and Murphy (2007) explore how the everyday activity of education instantiates a regime of gendered learning in alignment with the male and female binary. The authors' suggest that the cultural legacies of subjects imbue teachers' gaze, and without an awareness of how these legacies are woven with assumptions of gender, pedagogic practices reproduce the core gendered identity 
that they carry. The territorialisation of knowledge is most clearly illustrated within the science laboratory, where the masculine identity offers legitimacy and agency to boys, allowing their behaviour to go unregulated by teachers. Yet for girls the incongruence of femininity and the scientific means that their behaviour becomes salient and suspect, with their entitlement to learn being denied.

SEL may be mapped onto these same gendered hierarchical schemas due to the system of emotional pedagogy and assessment that has been introduced (Craig 2007; Matthews, Zeidner, and Roberts 2004). Students' positionality is determined by their performance of appropriate emotional repertoires, but also, somewhat ironically, by their capacity to empty this educational experience of emotion (Proctor 2013). As Kenway and Youdell (2011, 132) contend, SEL seems 'not to invite emotion into education, but to corral and contain it, to subdue and correct it within the rationality which it might otherwise exceed'. Gillies (2011) expands on this point, asserting that in the process of learning proper emotion, students must be able to suspend and survey affect, transforming it through the application of the intellect. Thus, the value attached to the capacity to leave emotional development uncontaminated by emotion serves 'as part of a discursive web of positioning and defining pupils against explicit and implicit ideals that are racialised, classed and gendered' (Gillies 2011, 191).

This article considers the emergence of gendered hierarchical binaries within the context of SEL interventions. It commences with an exploration of how these binaries are instantiated through the micro-practices of emotional pedagogy, which are informed by educational practitioners' latent assumptions around the gendered nature of emotionality. Elicitation of such hierarchical schemas is imperative to understanding how SEL interventions may give rise to differential learning experiences. Moreover, in understanding the role of educational practitioners in inculcating students' with gendered emotional subjectivities, this paper identifies potential opportunities to mitigate the emergence of new forms of educational inequalities. The importance of attending to such gendering practices is supported in the second part of the paper, which presents students' accounts of intervention participation, and how constrained opportunities for the performance of emotion may conclude with unintended and even detrimental learning experiences.

\section{Method}

The data presented in this paper were generated with four state-funded, mixed-sex comprehensive schools in South Wales. Three of the schools Ysgol-y-Dyffryn, Ysgol-y-Glyn and Ysgol-y-Cwm - are located in the postindustrial town of Pen-y-Cymoedd. All three predominantly educate white, 'working' class students, with participants often drawing upon notions of 'roughness' to define their socio-economic positioning. Serving as a 
counterpoint to these schools is Ysgol-y-Foryd in the small town of Castell Mawr. Students here are also largely white, but their socio-economic background is far more polarised, with the school catering to 'middle' class families and those who live on neighbouring housing estates. Study participants predominately lived on these estates. It is worth noting that the demographics of participants in this study meant that gender constituted the primary indices of difference, thus justifying the scope and focus on this paper.

Schools were identified for participation owing to their delivery of a SEL learning intervention, the Student Assistance Programme (Carnwell and Baker 2007; Carnwell, Baker, and Wassell 2008; Watkins 2008). Borne out of the recovery movement, the programme was developed in the USA during the early 1980s. It has been incrementally rolled out in Wales since 2003 and has been recommended by the Welsh school inspectorate as best practice in managing challenging behaviour (Estyn 2006). The intervention constitutes a whole-school approach, in the sense that it provides a comprehensive platform of activities that combine to transform the educational context and promote SEL. A central element is the student support group. Comprising two trained staff members and eight to 12 students, the group meets weekly, for one to two lesson periods, for a duration of eight weeks. Sessions explore various aspects of SEL, including emotional defence mechanisms, the subliminal transmission of family rules and the exercise of emotional control. Learning adheres to a pre-specified format, with staff members first relaying and modelling appropriate emotional displays, before students take turns to participate.

The student support group served as the primary study site, with participant observation being conducted with one group in each school. These groups included a total of 41 students aged 12-14, and eight staff. The three groups in Pen-y-Cymoedd were mixed sex, while the group at Ysgol-y-Foryd was solely made up of boys. Students had generally been referred to the intervention by school staff due to known family or educational problems, which had manifested in social withdrawal or challenging behavioural repertoires, as defined by the school (Evans, Scourfield, and Murphy 2014). The privileging of participation over observation ensured that the researcher partook in the sessions in the same manner as the students, engaging in activities and displaying the same degree of emotional disclosure. This method was utilised because of its capacity to explore the intervention in situ, offering an invaluable insight into the immediate and somewhat uncensored reactions and interactions within the group, thus hopefully eliminating some of the discrepancy between reflection and reality (Brunk 2001).

Following completion of the student support groups, both students and school staff were provided with the opportunity to discuss their experiences. One or two focus groups were conducted with students, with the groups retaining the same composition as the intervention (Kitzinger 1994). Taking 
advantage of a pre-existing set of relationships prevented the groups from becoming too much of an intimidating experience, with peers offering a comforting and familiar presence. Semi-structured interviews were conducted with the eight staff members (Gray 2004). Broadly guided by a set of questions, but privileging the interpretations and meanings of the individual, these interviews explored staff's decision-making during delivery and their perceptions of both the students' and their own emotional subjectivities. Cardiff University granted ethical approval for this study.

\section{Results}

The first part of the results discusses emotional pedagogic strategies adopted by educational practitioners in the course of intervention delivery and how they work to introduce gendered hierarchical binaries. Such micro-practices reflect gendered assumptions about the nature of SEL, whereby girls are deemed willing to demonstrate emotionality and boys are seen as estranged from SEL due to an ideologically prescribed masculinity. However, although gendering strategies are intended to provide engaging and relevant learning opportunities, the second part of the results reveals a significant incongruence between practitioner and students' accounts. Indeed, the constraints placed on the performance of emotion can make SEL interventions impossible spaces to inhabit, leading to unintended and even detrimental learning experiences.

\section{Exploring the gendering strategies of the emotional pedagogue}

\section{'Go on, just have a go': encouraging emotional expression}

Central to the ethos of the Student Assistance Programme is the social, emotional and reputational security of students. To this end, students are requested to adhere to the dictum of 'what's said in group stays in group' (Watkins 2008). Equally, facilitating staff are required to offer a nurturing environment where participants are not exposed to judgement, censure or punishment. This acceptance should primarily manifest through unresponsiveness to students' contributions; facilitators must passively receive without recognition. However, for many of the school staff partaking in this study, there was a perceived need to deviate from this model. Students' unfamiliarity with emotionally imbued spaces, combined with the intervention's Americanised vernacular, led to the facilitators proffering encouragement, and throughout the sessions they could often be found coaxing and cajoling. Ms Davies, a learning support assistant at Ysgol-y-Glyn, was amongst the most vocal in suggesting the need to be both physically and verbally demonstrative in their support during the unfolding of students' disclosures: 
I think we tended to stick with the book, with the activities within the book. The only thing I would say is that sometimes that we maybe veered off was, in, when, when we done it as a course we weren't allowed to respond, or um, interrupt. But I think sometimes, the children need a bit of encouragement to speak about things, so I'd say maybe if they're telling um, us about like a story. I, you'd think they need some reassurance or maybe, 'oh yeah', and maybe ask a question just to, you know, encourage them to share, cos sometimes they're looking around just for you to acknowledge that 'is this alright?' sort of thing. So, I think that's the only thing we sort of maybe done our own thing on. (Ms Davies, Ysgol-y-Glyn)

Despite such statements suggesting the indiscriminate provision of encouragement and reassurance, staff members' implicit gendered assumptions were evident, because girls served as the primary focus of their attention. This differential treatment characterised many of the interactions in the support group at Ysgol-y-Glyn, which consisted of 12 Year Eight students, and included three boys and nine girls. These students had primarily been referred to the intervention due to their social withdrawal and problematic peer relationships, and as a result many of them were shy and reticent in emotionally exposing themselves to others. The facilitators' sought to address this hesitancy by pushing the girls to take part in the activities, repeatedly asking them to 'have a go'. The boys were notably absent from these coercive efforts, as evidenced during one session where students were required to describe a difficult situation when someone had exercised emotional control over them:

Ms Davies asked everyone to close their eyes and think of a time that someone tried to control their thoughts or feelings, and the feeling they had as a consequence of this. After a couple of moment's silence she asked us to open our eyes, and gesturing with her hand, she indicated that we would move in a clockwise direction to share. Kyle, who was immediately on her left, slumped over the desk. Noticing this, Ms Davies changed her mind and said that we would move counter-clockwise instead. This meant that Gemma was first to take her turn. She said she did not really understand and Ms Davies explained again what was expected. Gemma claimed she could not think. Ms Morgan asked her about a time when someone had tried to control her. She reluctantly told us about an incident where Miss Hewitt had pushed her and spat in her face. Ms Morgan pushed her to engage further, asking how she felt about this experience. Gemma claimed she wasn't bothered. After some further prodding she admitted she was angry. Both facilitators nodded, saying 'well done' and 'thank you'. (Field notes, Ysgol-y-Glyn)

Reflective discussions around the rationale for this gendered construction of learning experiences was often underpinned by the notion of 'willing'. Despite an assumption that all students were inherently capable of meaningfully engaging in SEL, it was girls' 'willingness' to share that marked them out as targets for encouragement and praise. As Ms Davies commented: 'I think obviously with the three boys who were in the group, they were a bit, 
they didn't really want to, you know, speak up ... you've got some, like Faye, who was quite open and she was willing'. In focusing on the desirability of emotionality over alexithymia for the female subject position, facilitators routinely elided their role in creating willing subjects. Equally, preoccupation with willingness obscured underlying tensions around proof of learning. Resonating with established debates around the construction of the ideal learner as a docile body and disembodied mind, feminist critiques have highlighted the positioning of girls as mindless bodies (Davies 2005; Gillies 2011). Thus while the physically and emotionally detached boy is assumed to embody the normatively desirable student, similar performances by girls only serve to suggest their intellectual deficiencies. They are therefore compelled to offer proof of their competence, and in the case of the Student Assistance Programme, this comprised of routine sharing.

\section{'He's taking it in': permitting passive learning}

In contrast to staff members' concerted efforts to encourage emotional disclosures amongst girls was their endorsement of boys' passivity, with compliance and docility being perceived as an adequate and sufficient marker of success. Indeed, 'taking it in' became a trope that staff regularly drew upon in order to both describe boys' responses and to evidence their development through the internalisation of the learning process (Walkerdine 1989). Matthew, a 13-year-old student at Ysgol-y-Dyffryn, epitomised the passive learner. Located on the margins of education, Matthew regularly split his time between the classroom and the Pupil Referral Unit, as his behaviour was deemed to be extremely disruptive and recalcitrant. At the time of the study Matthew was at risk of permanent exclusion from the school, and the Student Assistance Programme had been employed as a last attempt to keep him in mainstream education.

Matthew's peers offered an insight into both his notoriety and status within the school. He served as a romantic interest for many of the girls, who were often coy and deferential in his presence. The other two boys in the group, who had been referred due to their social withdrawal and lack of friendships, appeared intimidated and shied away from directly interacting with him. In return, Matthew rarely sought to engage with the other students, and his reactions to their session contributions were apathetic. His own participation was also limited, and when his turn came around he would invariably lower his head, stub his toes into the floor and mutter that he did not know or could not think of anything to say.

Ms Richards and Ms Shields, the two facilitating staff members, did not interpret this passivity as a marker of disinterest, however, but imbued it with a set of meanings that were aligned with the aims of the group and their own gendered assumptions about social and emotional development. Through discussions around the broader context of Matthew's social world, 
and the competing subject positions that laid claim to his identity, both facilitators highlighted a perceived incommensurability between the normative masculine discourse that governed young boy's subjectivities in the South Wales valleys and the learning undertaken in the intervention. Particular reference was made to the naturalness and necessity of physicality and hardness rather than emotionality and vulnerability:

Rhiannon: So Matthew will carry on?

Ms Richards: I don't think Matthew needs it, because he knows, he knows the principles I think. And he's quite intelligent. He's just in with the wrong crowd. I think the school may want him to continue as a sort of discipline thing. The PRU [Pupil Referral Unit] thing. I think will happen. I don't think he needs it as such. That's how I feel. But then again, like I said, it's maintaining the hard man image, Matthew, more than anything else.

Ms Shields: Oh yeah. Once he goes from here, he's a different boy altogether.

Ms Richards: Cos you get him on a one to one basis, you can have a tidy conversation with him. I've seen a different side to him down the PRU one to one.

Ms Shields: Like the men out there, been doing that allotment out there. They asked me Wednesday could he go out there because there was no body there to supervise him. Because Lisa [education officer] wasn't in. And I asked Dave [caretaker] and he said yes, mean as they asked for him. And he worked all day with a wheelbarrow. I think that's his.

Ms Richards: Yeah. I think he's gonna be one that works with his hands.

Ms Shields: Be hands on, you know.

In order to allow Matthew to move beyond this impasse and succeed in the group Ms Richards and Ms Shields claimed his passivity to be an act of compliance, acceptance and even endorsement of the learning experience. In light of the perceived inherency of Matthew's physicality to his masculine subjectivity, both facilitators felt that any act of docility was evidence of progress. Meanwhile, the submissiveness of his body left him both physically and emotionally receptive to the intervention, allowing the absorption of the lessons that were unfolding around him:

Ms Richards: He's taking it in definitely. He proved that, he's taking it in.

Rhiannon: What did he say?

Ms Richards: I can't remember what he said now. But.

Rhiannon: About working in a team?

Ms Richards: Yeah. But he was right. Whatever it was he was right.

Ms Shields: He is taking it in. He might not say often.

Ms Richards: A lot of it with him is maintaining the hard man image.

Ms Shields: Yeah, yeah. Cos he was out there earlier on.

Rhiannon: Do you find that's a problem with a lot of the boys though? Do you notice a difference between the boys and the girls? 
Ms Shields: Different types of boys. Luke, the other boy, is not at all like him. Luke is more quiet and laid back, not like Matthew. And the other one. What was the other one we had? Darren. He doesn't come anymore does he? Matthew's got to have an image. He's got to be hard and big.

Rhiannon: What about Luke?

Ms Richards: He's another one who's taken it on board but is reluctant to speak about it. Because there's no mum there and I think the granddad passed away.(Interview, Ysgol-y-Dyffryn)

The manifestation of facilitators' gendered assumptions increasingly permeated the students' understanding of boys' and girls' emotional subjectivities, thus reinforcing the notion of difference. Matthew became complicit in applying the concept of 'taking it in', agreeing that he was indeed absorbing intervention messages. Other students also became reliant on the trope to explain the boys' passivity, with Hayley summarising their response with the refrain 'the quieter you are, the more you take in'.

\section{'They wouldn't understand that': setting emotional boundaries}

Alongside the subtle gendering strategies employed was the more overt and conscious effort to adapt the intervention to encourage cultural congruency, particularly with regard to the normative discourses that were thought to scaffold boys' emotional expression. In alignment with the inventory of cognitive and behavioural states that have characterised a taxonomy of ideologically prescribed masculinities in western societies (Connell 1987; Connell and Messerschmidt 2005; Haywood and Mac an Ghaill 2012), facilitators were keen to re-orientate tasks in order to focus on displays of aggressiveness, competitiveness and anger. These adjustments were perceived to be most desirable at Ysgol-y-Foryd, which comprised a tumultuous friendship of eight boys who had been referred to the intervention due to their challenging and disruptive behaviour within the classroom, combined with a more general disregard for school structures and discipline procedures. Existing outside dominant discourses of academic success, and being amongst the most socio-economically deprived students in the school, these individuals recognised the limited discursive options available and often responded by overinvestment in a reactionary form of masculinity (Benjamin 2001).

The group's facilitator, Ms Parry, projected an awareness of the boys' necessity to maintain compliance with the hegemonic masculine form, and aimed to make concessions through the stringent scaffolding of participation. Prior to the commencement of each session, the facilitator could often be found critiquing activities and identifying opportunities to make them more sympathetic to the ostensible needs of the students:

Ms Parry took a seat at the table by the window and pulled out the handbook. After a few moments of rifling through the various sessions she claimed that 
the language wasn't right for them. It was too Americanized. Instead of saying 'what allows me to be close to you' the facilitator wanted to change it to 'what allows me to be friends with you'. Ms Parry maintained that this would be more acceptable as the boys wouldn't get embarrassed and we could avoid the usual mockery and joking. Closing the book she said 'girls might do it, but boys won't'. (Field notes, Ysgol-y-Foryd)

These modifications continued throughout the sessions, with Ms Parry reflexively adjusting the intervention in an immediate response to any lapses in concentration or prolonged periods of silence. When these episodes of disengagement followed the relaying of abstract and nebulous theoretical concepts, the facilitator would provide gendered examples of emotion or experiences in an effort to make the learning resonate. Control became a recurrent motif that was used to both explore and define the students' emotionality, with discussions centring on their experiences of the subject position of volatile, aggressive boy:

As usual the group started with the sharing of a challenging life event. Everyone sat in silence, swinging on their chairs or kicking their heels into the floor. After a few moments Ms Parry asked each individual to share in turn. We slowly moved around the group but no one was keen to contribute, each student saying they couldn't think of anything off the top of their heads. Ms Parry kept suggesting topics, such as getting into a fight, problems in schools, getting angry, or doing something that they regretted. Liam kept nudging Andrew saying 'that's you, that's you'.

The final task required the students to share their experiences of taking control over their own thoughts, feelings and behaviour. Again I noticed Ms Parry introduce a new version of this activity by asking the students if they had learned any new ways of controlling their anger. A resolute 'no' was expressed throughout the group. Jayden continued that if someone came on to him, he had to stand up, take the fight, and 'knock them out and then dump on them in front of everyone'. If he didn't everyone would call him a pussy. Ms Parry asked if this really mattered. The boys insisted that it did, as it was not just the person starting a fight who would 'take the piss', but their friends also. Although they knew it might be better to control their anger, walking away from a fight just wasn’t an option. (Field notes, Ysgol-y-Foryd)

Construction of an emotional hierarchy was clearly evident throughout Ms Parry's act of emotional pedagogy. While bounding the boys' social and emotional development, the facilitator simultaneously admonished them for lacking the strength to understand and control both the nature and consequences of their emotions. These contradictory claims on the students' identity ensured that the intervention became an increasingly impossible space for them to inhabit, and success as the 'emotional elite' was placed completely beyond their reach. 


\section{Creating the confessional: responses to emotionally structured spaces}

Students' responses to staff's effort to inculcate them with a gender through the process of emotional pedagogy were complex and conflicted, illustrating both the agency of the individual and the strength of structuring discourses. Fraught performances were often explained by the spatial context, and the stage upon which intervention actions and interactions played out (Kenway and Youdell 2011; Proctor 2013). Across the four schools the groups were held in empty classrooms, meeting rooms or the library, and the delivery of sessions during lesson periods suggested a similarity with general academic learning. Resonance with the classroom context ensured that the intervention became a microcosm of students' everyday world, replicating relational dynamics and endorsed cultural and social norms. Manifestation of facilitators' gendered assumptions only served to reinforce awareness of the permeability and fragility of the 'safe' space. Hence, before the intervention had even commenced, students were clearly socially positioned, trying to carve out their own place within an emotional space not of their making (Proctor 2013).

Although all students demonstrated awareness that ostensibly external discourses could infiltrate the intervention, the group at Ysgol-y-Foryd were particularly conscious that efforts to saturate the space with their emotions would be interpreted as transgressive behaviour that contravened sanctioned masculine norms. The intervention thus took on the semblance of a confessional, serving as a highly regulated space where students felt coerced, policed and reprimanded by both facilitators and peers. As a result, many students became resigned to their ascribed subject position and there was continued negotiation over the extent of the disclosures that could be offered up amidst fears that emotional narratives could serve as a form of currency within the larger peer group, being traded in order gain reputational advantage:

Jayden: $\quad$ There's some people I won't say stuff in front of. That's Liam. Rhiannon: And why?

Jayden: I'm not saying he'll go and tell someone but he'll keep it against me.

Rhiannon: He'll hold it against you?

Jayden: If I said something he'll hold it against me. And I know he will. He would end up telling everyone. Trust.

Rhiannon: What do you think he might hold against you?

Jayden: I don't know. I don't know. It's just if I said something he would end up telling someone. I know he would. And I know that for a fact.

Rhiannon: So you'd be waiting for him to tell?

Liam: Nah, if it was something serious. But if it was something shit.

Rhiannon: But what's the difference between something serious and shit? 
Liam: If it's something shit like 'oh, my dad's sleeping with someone'. Yeah that's shit. But if it's something serious. If it was something serious like 'my dad whipped me' then obviously. (Focus group, Ysgol-y-Foryd)

However, in juxtaposition to these highly regulated and normative performances were glimpses of a set of students who were bored by the banality of being another 'working' class boy. Dissatisfied with the subject positions offered through the gendered emotional pedagogy, they were often keen to challenge and explore other emotional repertoires. Indeed, many of them spoke about the importance of relationships with family members that existed outside of normative discourses of masculinity, citing the significance of grandmothers, who created safe and exploratory emotional spaces. Despite initial indications that the intervention would provide similar opportunities to problematise dominant discourses of masculinity, the reification of hegemonic performances only served to foster resentment. Frustrations were evident throughout reflective discussions about facilitating staff, with students drawing on provocative sexist and racist language to demonstrate their heightened emotion. Students expressed particular disappointment with Ms Parry and were angry at her repetitive, unimaginative and disinterested interactions with them. Reliance on the intervention handbook was seen as symptomatic of Ms Parry's failure to look beyond the collective and see them as individuals with distinct social and emotional experiences and needs:

$\begin{array}{ll}\text { Rhiannon: } & \text { Right ok, let's go back to Ms Parry. } \\ \text { Neil: } & \text { Bitch. } \\ \text { Leighton: } & \text { Slag. } \\ \text { Neil: } & \text { Whore. } \\ \text { Rhiannon: } & \text { So what do you dislike about Ms Parry doing the group? } \\ \text { Callum: } & \text { She's a slag. } \\ \text { Neil: } & \text { She just doesn't talk about anything, she just says the same } \\ & \text { thing every week. } \\ \text { Callum: } & \text { I don't mind her. } \\ \text { Liam: } & \text { Mr Rees is a bit of a dick though. I don't actually like him. } \\ \text { Rhiannon: } & \begin{array}{l}\text { And you know when they tell you about their own lives, how } \\ \text { do you think Mr Rees is different to Ms Parry? }\end{array} \\ \text { Liam: } & \text { Cos she's a slut. } \\ \text { Jayden: } & \text { Ms Parry's just not very nice. } \\ \text { Neil: } & \begin{array}{l}\text { She's just weird. She says the same thing out of the book } \\ \text { every day. }\end{array} \\ \text { Callum: } & \begin{array}{l}\text { Yeah. [High-pitched voice] 'What's said in group stays in } \\ \text { group'. }\end{array} \\ \text { Gareth: } & \text { [Posh voice] 'What's said in group stays in group'. } \\ \text { Jayden: } & \text { I don't like it. I don't like her sessions.(Focus group, Ysgol- } \\ & \text { y-Foryd) }\end{array}$


Similar sentiments were expressed in relation to Mr Rees, a youth worker who had been selected to run the intervention owing to a long and generally positive relationship with the students. The effectiveness and desirability of Mr Rees's presence was initially felt, with the group appreciating similarities in their backgrounds and personalities. As one student commented: 'He's just like us. He just sits there and chillaxes and can't be bothered'. However, as the intervention unfolded the students quickly grew tired of Mr Rees's performance, and were irritated by his failure to fully commit and engage in the learning process. This annoyance was notably manifest in their response to Mr Rees's decision to take a holiday rather than attend the intervention:

$\begin{array}{ll}\text { Rhiannon: } & \begin{array}{l}\text { Do you feel any different perhaps about Mr Rees now and } \\ \text { before you came? }\end{array} \\ \text { Jayden: } & \text { Nah. } \\ \text { Leighton: } & \text { I thought he was. } \\ \text { Neil: } & \text { I think he's a lazy shit who never, who never turns up. } \\ \text { Callum: } & \begin{array}{l}\text { Yeah. } \\ \text { Leighton: }\end{array} \\ \text { I thought he was safe before we came to these groups. } & \begin{array}{l}\text { I thought, I thought he put quite a lot of effort in to do things } \\ \text { and then he couldn't even be bothered to turn up. }\end{array} \\ \text { Gareth: } & \begin{array}{l}\text { I thought he might have more things on. Like more serious } \\ \text { things. }\end{array} \\ \text { Leighton: } & \begin{array}{l}\text { But then we found out that he'd gone tanning instead of com- } \\ \text { ing here. }\end{array} \\ \text { Liam: } & \text { Paki prick. }\end{array}$

Through employment of Mr Rees as a template of the ideologically prescribed masculinity within South Wales, predominantly through his apathy towards emotional development and his 'can't be bothered attitude', the complex layering of the boys' own masculinity was evident; the assigned hegemonic form was both desired and derided. Indeed, as the intervention unfolded the students increasingly oscillated between these two positions, aligning themselves with the masculinity performed by $\mathrm{Mr}$ Rees before resisting and resenting the limited and ultimately dissatisfactory subject position on offer.

\section{Discussion}

The great difficulty for human beings - a difficulty that may impede not only our moral characters but our entire wellbeing - is 'tracing the lawful bounds' of our responses, and particularly our emotions. (Cigman 2012, 452)

In Ruth Cigman's (2012) trenchant critique of the wellbeing agenda, the author troubles the tracing of boundaries around both the experience and expression of emotion. Questions surround the morality of compelling 
young people to emote in alignment with a normatively prescribed criterion and the lawfulness of creating emotional hierarchies in light of the disparate contexts and needs of individual lives. Yet despite the evident importance of attending to both the nature and consequences of these boundaries, there remains limited empirical research as to the social, material and cultural discourse that inform their inscription (Gillies 2011). Gender has been a notable omission, and this article has sought to progress understanding of the micro-politics and practices through which it makes itself known. Specifically, it has considered how educational practitioners draw upon gender throughout acts of emotional pedagogy in order to structure the development of students' emotional subjectivities, while simultaneously employing it as an organising framework to differentiate and position them. Without an awareness of how this pedagogy instantiates a regime of gendered SEL, there is a risk that the hierarchical schemas that increasingly pervade this learning arena (Craig 2007; Matthews, Zeidner, and Roberts 2004) will produce and reproduce gendered educational inequalities, similar to those that have troubled academic outcomes and inspired a number of moral panics (Ivinson and Murphy 2007).

The emotional pedagogy delivered by educational practitioners' participating in the study drew upon three key gendering strategies. These acts were predominantly borne out of staff's effort to promote inclusivity through the introduction of cultural adaptations. They centred on inviting girls to suspend affect, and to engage in the intellectual exercise of analysing and articulating emotions, either due to a presumed willingness or compulsion to prove their educational capacity. In contrast, boys were perceived as privileging the expectations of the hegemonic masculine form; and thus despite being understood as having an innate ability to be emotionally literate, they were permitted to passively participate, with their docile bodies serving as a signifier of success (Hall et al. 2004; Walkerdine 1989).

However, the notion of inclusivity is underpinned by the promotion of difference rather than equality, and, as Benjamin (2003) astutely comments, difference seldom wins out over dominance. Hierarchies prevail, and the idiosyncratic performances of one individual are compared and categorised in relation to another. A duality of gendered emotional hierarchies played out within the Student Assistance Programme. Firstly, in resonance with feminist debates that critique the mapping of the mind and body distinction onto the male and female binary (Gillies 2011), it is apparent that the docile male and female bodies are interpreted differently by teachers. The physically subdued boy, who epitomises the ideal learner, can be contrasted with the mindless bodies of girls, who carry a burden of proof and must overtly demonstrate their social and emotional competency. In juxtaposition, the second hierarchy sees the assignment of the 'emotional failure' subject position to boys amidst an acceptance of their omission from SEL. In presuming the desirability of the hegemonic masculine discourse, school staff restricted 
learning opportunities for boys, yet would simultaneously emphasise their hope for these individuals to intellectualise their emotions and meaningfully share them aloud. The coercion of girls to perform emotion only served to amplify the apparent estrangement of boys from SEL. Thus this type of intervention may be an impossible space for many, with them becoming increasingly caught up in the tension between competing subject positions.

The presentation of students' experiences of intervention participation and the incongruence with practitioners' accounts further illustrate the potential iatrogenic impacts of well-intended emotional pedagogy, which has been increasingly documented elsewhere (Evans, Scourfield, and Murphy 2014). Indeed, the identities of students in this study were fraught and fragile, with many feeling both resigned to their ascribed subject position and annoyed at being corralled by such constricted and suffocating boundaries of expression. Such contradictions in accounts illuminate the importance of attending to both perspectives, while also demonstrating the necessity of privileging the nuance and complexity of young people's identity work in relation to emotionality when theorising SEL interventions. Specifically, failure to move beyond conceptually inadequate notions of essentialist and intelligible genders means that students are being unnecessarily coerced into gendered emotional hierarchies that do not reflect their reality. Thus interventions and emotional pedagogy more broadly need to acknowledge the multifarious understandings and manifestations of gender, separating them from their ontological premise within physiology (Benjamin 2001; Haywood and Mac an Ghaill 2012; Renold 2001). In rejecting the primacy of masculinity and femininity as the only available analytical categories, emotional spaces can be opened up, with students learning the skill sets required for the unique social, material and cultural demands of their individual world.

Beyond the implications for SEL intervention, the propensity for gendered pedagogic practices to relativise students' emotional subjectivities clearly suggests the necessity of critically engaging with, and potentially reorientating educational policy around social and emotional wellbeing. Existing school effectiveness frameworks centre on the mitigation of educational disparities through a systems approach that addresses personal, social and emotional skills (Welsh Assembly Government 2008). However, there remains little regard for the fact that this skill development may introduce new forms of inequalities that only serve to exacerbate the existing and seemingly intractable disadvantage that many young people experience. There has been an equal omission of the increasing role that educational professionals have to play in the delivery of emotional pedagogy, despite not receiving the training needed to scaffold and inform this responsibility (Kidger et al. 2010). Indeed they may serve as a primary mechanism in the generation of inequalities, and more adequate support and education is required. Such recommendations form part of a broader critique of how we think about the SEL within educational settings (Craig 2007; Watson et al. 
2012); rather than being seen as the solution to the failings of the system, it needs to be understood as being part of the problem and remedies need to be fully explored and addressed.

\section{Conclusion}

This article has sought to rectify the continued dearth of empirical research exploring how social, cultural and material discourses inform the meaning and expression of emotion within school-based SEL interventions. With a specific focus on how gender makes itself known through the micro-politics practices of intervention interactions, the article has considered how the emotional pedagogy performed by educational professionals instantiates gendered hierarchical binaries. Such pedagogic practices suggest the potential for SEL interventions to introduce new forms of educational inequalities, and policy and practice need to be diligent in not promoting the wellbeing agenda as a panacea for existing problems with the educational system, without acknowledgement of its potential to exacerbate disadvantage through the inscription of additional indices of difference. Meanwhile, student's fraught responses to pedagogues' efforts to inculcate them with a stringent gender indicates an evident need to open up interventions to accommodate the complex emotional competencies and performance that young people require within their particular social worlds.

\section{Disclosure statement}

No potential conflict of interest was reported by the author.

\section{Funding}

This work was funded by the National Institute for Social Care and Health Research (NISCHR) in Wales. The views expressed in this publication are those of the authors and not necessarily those of NISCHR. The work was undertaken with the support of The Centre for the Development and Evaluation of Complex Interventions for Public Health Improvement (DECIPHer), a UK Clinical Research Collaboration Public Health Research: Centre of Excellence. Funding from the British Heart Foundation, Cancer Research UK, the Economic and Social Research Council (RES-590-28-0005), the Medical Research Council, the Welsh Government and the Wellcome Trust (WT087640MA), under the auspices of the UK Clinical Research Collaboration, is gratefully acknowledged.

\section{References}

Adi, Y., A. Schrader McMillan, A. Killoran, and S. Stewart-Brown. 2007. Systematic Review of the Effectiveness of Interventions to Promote Mental Wellbeing in Primary Schools: Universal Approaches Which Focus on Prevention of Violence and Bullying. London: National Institute for Clinical Excellence. 
Benjamin, S. 2001. "Challenging Masculinities: Disability and Achievement in Testing times." Gender and Education 13 (1): 39-55.

Benjamin, S. 2002a. The Micro Politics of Inclusive Education: An Ethnography. Buckingham: Open University Press.

Benjamin, S. 2002b. "Reproducing Traditional Femininities? The Social Relations of 'Special Educational Needs' in a Girls' Comprehensive School." Gender and Education 14 (3): 281-294.

Benjamin, S. 2003. "What Counts as 'Success'? Hierarchical Discourses in a Girls' Comprehensive School." Discourse: Studies in the Cultural Politics of Education 24 (1): 105-118.

Brunk, L. 2001. "Into the Community." In Handbook of Ethnography, edited by P. Atkinson, A. Coffey, D. Delamont, J. Lofland, and L. Lofland, 80-91. London: Sage.

Carnwell, R., and S. A. Baker. 2007. "A Qualitative Evaluation of a Project to Enhance Pupils' Emotional Literacy through a Student Assistance Programme.” Pastoral Care in Education 25 (1): 33-41.

Carnwell, R., S. A. Baker, and C. Wassell. 2008. "Tackling Behavioural Problems in the Classroom Using a Student Assistance Programme." In Effective Practice in Health, Social Care and Criminal Justice: A Partnership Approach, edited by R. Carnwell and J. Buchanan, 160-176. Buckingham: Open University Press.

Cigman, R. 2008. "Enhancing Children." Journal of Philosophy of Education 42 (3-4): 539-557.

Cigman, R. 2012. "We Need to Talk about Well-Being." Research Papers in Education 27 (4): 449-462.

Connell, R. W. 1987. Gender and Power: Society, the Person and Sexual Politics. Cambridge: Polity Press in association with Basil Blackwell.

Connell, R. W., and J. W. Messerschmidt. 2005. "Hegemonic Masculinity: Rethinking the Concept." Gender and Society 19 (6): 829-859.

Craig, C. 2007. The Potential Dangers of a Systematic, Explicit Approach to Teaching Social and Emotional Skills (SEAL). Glasgow: Centre for Confidence and Well-being.

Davies, E. 2005. "Docile Bodies and Disembodied Minds." Educational Theory 46 (4): 525-543.

Department for Children, Schools and Families. 2007. Social and Emotional Aspects of Learning for Secondary Schools. Nottingham: DCSF Publications.

Department for Education and Skills. 2005. Social and Emotional Aspects of Learning (SEAL): Improving Behaviour, Improving Learning. DfES Publications: Nottingham.

Durlak, J. A., R. P. Weissberg, A. B. Dymnicki, R. D. Taylor, and K. B. Schellinger. 2011. "The Impact of Enhancing Students' Social and Emotional Learning: A Meta-Analysis of School-based Universal Interventions." Child Development 82 (1): 405-432.

Education Scotland. 2013. Inspection Advice Note 2013-14. Taking Account of Curriculum for Excellence National Expectations in Inspections.

Estyn. 2006. Behaviour in Wales: Good Practice in Managing Challenging Behaviour. Cardiff: Estyn.

Estyn. 2010. Common Inspection Framework. Cardiff: Estyn.

Evans, R. E., J. B. Scourfield, and S. Murphy. 2014. "The Unintended Consequences of Targeting: Young People's Lived Experiences of Social and Emotional Learning Interventions." British Educational Research Journal. doi:10.1002/berj.3155. 
Gillies, V. 2011. "Social and Emotional Pedagogies: Critiquing the New Orthodoxy of Emotion in Classroom Behaviour Management." British Journal of Sociology of Education. 32 (2): 185-202.

Goleman, D. 1996. Emotional Intelligence: Why It Can Matter More than IQ. London: Bloomsbury Publishing.

Gray, D. E. 2004. Doing Research in the Real World. London: Sage.

Greenberg, M. T., C. Kusche, E. Cook, and J. Quamma. 1995. "Promoting Emotional Competence in School-Aged Children: The Effects of the PATHS Curriculum." Development and Psychopathology 7 (1): 117-136.

Hall, K., J. Collins, S. Benjamin, M. Nind, and L. Sheehy. 2004. "Saturated Models of Pupildom: Assessment and Inclusion/Exclusion." British Educational Research Journal 30 (6): 801-817.

Haywood, C., and M. Mac an Ghaill. 2012. “'What's Next for Masculinity?' Reflexive Directions for Theory and Research on Masculinity and Education." Gender and Education 24 (6): 577-592.

Ivinson, G., and P. Murphy. 2007. Rethinking Single-Sex Teaching: Gender, School Subjects and Learning. Single Sex Schooling. Maidenhead: Open University Press.

Kenway, J., and D. Youdell. 2011. "The Emotional Geographies of Education: Beginning a Conversation.” Emotion, Space and Society 4: 131-136.

Kidger, J., D. Gunnell, L. Biddle, R. Campbell, and J. Donovan. 2010. "Part and Parcel of Teaching? Secondary School Staff's Views on Supporting Student Emotional Health and Well-Being." British Educational Research Journal 36 (6): 919-935.

Kitzinger, J. 1994. "The Methodology of Focus Groups: The Importance of Interaction between Research Participants." Sociology of Health and Illness 16(1): 103-121.

Matthews, G., M. Zeidner, and R. D. Roberts. 2004. Emotional Intelligence: Science and Myth. Cambridge: MIT Press.

Ofsted. 2013. The Framework for School Inspection. Manchester, NH: Ofsted.

Proctor, L. 2013. "Emotions, Power and Schooling: The Socialisation of 'Angry Boys'." Journal of Political Power 6 (3): 495-510.

Renold, E. 2001. 'Learning the 'Hard' Way: Boys, Hegemonic Masculinity and the Negotiation of Learner Identities in the Primary School." British Journal of Sociology of Education. 22 (3): 369-385.

Walkerdine, V. 1989. "Femininity as Performance." Oxford Review of Education 15 (3): 267-279.

Watkins, C. 2008. Student Assistance Programme Training UK. Phoenix, AZ: UK Student Assistance Training International.

Watson, D., C. Emery, P. Bayliss, M. Boushel, and M. McInnes. 2012. Children's Social and Emotional Wellbeing in Schools: A Critical Perspective. London: Policy Press.

Weare, K., and M. Nind. 2011. Promoting Mental Health of Children and Adolescents through Schools and School Based Interventions. Data Prev Project: Report of work package three.

Welsh Assembly Government. 2008. School Effectiveness Framework: Building Effective Learning Communities Together. Cardiff: Welsh Assembly Government. 